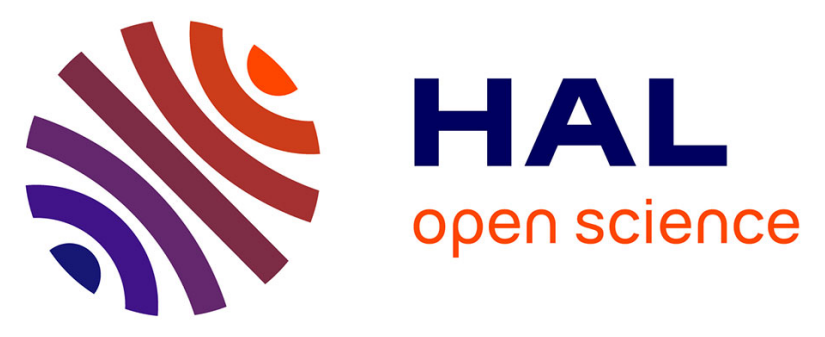

\title{
The BH3-mimetic ABT-737 targets the apoptotic machinery in cholangiocarcinoma cell lines resulting in synergistic interactions with zoledronic acid
}

Antonello A. Romani, Silvia Desenzani, Marina M. Morganti, Maria Cristina Baroni, Angelo F. Borghetti, Paolo Soliani

\section{To cite this version:}

Antonello A. Romani, Silvia Desenzani, Marina M. Morganti, Maria Cristina Baroni, Angelo F. Borghetti, et al.. The BH3-mimetic ABT-737 targets the apoptotic machinery in cholangiocarcinoma cell lines resulting in synergistic interactions with zoledronic acid. Cancer Chemotherapy and Pharmacology, 2010, 67 (3), pp.557-567. 10.1007/s00280-010-1345-6 . hal-00593405

\section{HAL Id: hal-00593405 https://hal.science/hal-00593405}

Submitted on 15 May 2011

HAL is a multi-disciplinary open access archive for the deposit and dissemination of scientific research documents, whether they are published or not. The documents may come from teaching and research institutions in France or abroad, or from public or private research centers.
L'archive ouverte pluridisciplinaire $\mathbf{H A L}$, est destinée au dépôt et à la diffusion de documents scientifiques de niveau recherche, publiés ou non, émanant des établissements d'enseignement et de recherche français ou étrangers, des laboratoires publics ou privés. 


\title{
The BH3-mimetic ABT-737 targets the apoptotic machinery in
}

\section{cholangiocarcinoma cell lines resulting in synergistic}

\section{interactions with zoledronic acid}

\author{
Antonello A. Romani ${ }^{1 *}$, Silvia Desenzani ${ }^{2 *}$, Marina M. Morganti ${ }^{3}$, \\ Maria Cristina Baroni ${ }^{4}$, Angelo F. Borghetti ${ }^{2}$ and Paolo Soliani ${ }^{1 \S}$ \\ ${ }^{1}$ Dipartimento di Scienze Chirurgiche, Sezione di Clinica Chirurgica e dei Trapianti d'Organo, \\ ${ }^{2}$ Dipartimento di Medicina Sperimentale, Sezione di Patologia Molecolare e Immunologia, \\ ${ }^{3}$ Dipartimento di Salute Animale; ${ }^{4}$ Dipartimento di Medicina Interna e Scienze Biomediche, \\ Università degli Studi di Parma
}

* These authors equally contributed to the article.

${ }^{\S}$ Corresponding Author:

Prof. Paolo Soliani, M.D.

Dipartimento di Scienze Chirurgiche,

Sezione di Clinica Chirurgica e dei Trapianti d'Organo,

via Gramsci 14, 43100 Parma, Italy

email: paolo.soliani@unipr.it 


\section{Abstract}

Purpose: In TFK-1 and EGI-1 cholangiocarcinoma cell lines zoledronic acid (ZOL) determines a S-phase block without apoptosis. Here we investigated the occurrence of apoptosis stigmata when ZOL is associated to the BH3-mimetic ABT-737.

Methods: In EGI-1 and TFK-1 cholangiocarcinoma cell lines untreated or treated with ABT-737 alone or in combination with ZOL, the pro-survival proteins pattern (BCL-2, BCL-XL, MCL-1, HSP72, HSP27) was investigated by biochemical criteria along with the occurrence of mitochondrial damage evaluated by cytofluorimetric analysis using a cationic dye.

Results: ABT-737 induced growth inhibition and significantly affected the colony-forming ability of both EGI-1 and TFK-1 cells. However, activated PARP-1 or/and caspase-3 cleavage (apoptosis markers) were detected only at the highest ABT-737 concentrations used. Combined treatment showed synergistic effect by converting the predominant cytostatic effect of ZOL into a cytotoxic one as shown by striking increment of mitochondrial-harmed cells along with PARP-1 activation and caspase-3 cleavage.

Conclusion: The lacking of apoptosis following ZOL treatment in these cholangiocarcinoma cell lines appears to be multifactorial and could be ascribed to the large constitutive expression of prosurvival proteins. The efficacy of ZOL treatment requires a concomitant unleashing of apoptosis by using a selective $\mathrm{BH} 3-$ mimetic as ABT-737. The rational targeting of specific components of the apoptotic pathway may appear a useful approach to improve the treatment of refractory or relapsed cholangiocarcinoma. Combined treatment could be further explored in vivo tumor model of cholangiocarcinoma 


\section{INTRODUCTION}

Cholangiocarcinoma is a malignant tumor that derives from bile duct epithelium. The incidence and the mortality rates of cholangiocarcinoma are increasing worldwide[1, 2]. At present, radical resection $(\mathrm{R} 0)$ is the only way to cure this disease[3,4]. Conventional anticancer treatments, such as chemotherapy or radiotherapy have, up to now, minimal impact on patients' survival with unresectable tumors[5, 6]. A recent prospective multicenter phase III study reveals that gemcitabine and cisplatin combination chemotherapy has a superior tumor response for advanced biliary tract cancer with a median survival times for the combination chemotherapy of 11.7 months and only 8.3 months for the single-agent gemcitabine[7, 8]. Unfortunately, the factors responsible for this relative unresponsiveness are not clearly understood.

The majority of conventional cytotoxic agents indirectly induce apoptosis through DNA damage and cell cycle arrest. However, malignant cells frequently acquire defects, including oncogene activation and/or deregulation of apoptotic signaling pathways, thus allowing them to evade apoptosis[9]. These deregulated pathways along with the high levels of toxicity frequently observed with traditional treatments, have prompt recent approaches to cancer therapy on targeting key components essential to tumor survival and disease progression[10]. This approach is aimed to circumvent acquired drug resistance and re-sensitize the malignant cell to apoptosis.

Recently, it has been reported that the ERK and AKT pathways play an important role in cholangiocarcinoma cell survival[11, 12]. Considering that ZOL, a third-generation of biphosphonates, facilitates the dislocation of RAS from cell membrane to cytosol by inhibiting post-translational prenylation and its membrane-anchorage, affects the activation of the downstream ERK and AKT signaling pathways[13], we have investigated this inhibitor in cholangiocarcinoma cell lines[14]. Our results indicated that ZOL-treatment determines S-phase arrest but fails to induce apoptosis even at concentrations above IC50. Similar results were also observed in prostate, breast and lung cancer cell lines. 
In human malignancies, the increased expression of pro-survival proteins (e.g., BCL-2, BCL-XL, BCL-W or MCL-1) is frequently observed and often associated with tumor progression, resistance to chemotherapy, and poor clinical outcome[15]. Constitutively high levels of BCL-2 or BCL-XL have been associated with a more aggressive malignant phenotype and/or drug resistance to various chemotherapeutic agents in hematologic malignancies and solid tumors.

The results showed by Okaro[16] and Harnois[17] performed on cholangiocarcinoma cell lines and pathologic specimens of patients affected by cholangiocarcinoma suggest a marked involvement of BCL-2 proteins family overexpression in tumor progression and aggressiveness. Accordingly, other authors reported a direct link between overexpression of some BCL-2 protein family members (such as MCL-1) and drug resistance in cholangiocarcinoma cell lines[18].

In the last few years have been developed small molecules that directly interact with pro-survival BCL-2 proteins. These agents mimic the action of $\mathrm{BH} 3$ proteins and by interacting with prosurvival BCL-2 proteins at their BH3-binding groove block them by sequestering $\mathrm{BH} 3$ proapoptotic proteins. At present, Obatoclax and ABT-737 are novel BH3-mimetics tested in clinical trials for hematologic and solid tumors.

The pan-BCL-2 family proteins inhibitor Obatoclax is an indole bipyrrole compound that inhibits with relatively low affinity most BCL-2 family members. In contrast, ABT-737 binds selectively BCL-2, to a lesser extent BCL-XL, BCL-W and MCL-1. By sequestering these pro-survival proteins, it promotes $\mathrm{BAX}$ and $\mathrm{BAK}$ oligomerization (via BIM) and ultimately programmed cell death. Consistent with the low affinity of ABT-737 for MCL-1, multiple reports suggested that high basal levels of MCL-1 expression are associated with resistance to ABT-737. For this reason the effectiveness of ABT-737 has been tested in tumors with low/absent MCL-1 or in combination with agents that inactivate MCL-1[19, 20].

Among those proteins directly or indirectly linked to the BCL-2 protein family, the heat shock proteins (HSPs) play key roles in inhibiting the cell death pathway at multiple checkpoints[21]. 
They can directly interact with members of the tightly regulated caspase-dependent cell death machinery upstream, downstream and at mitochondrial level. Interestingly HSPs, and in particular HSP72, can affect the caspase-independent death pathway[22], interacting with apoptogenic proteins such as the apoptosis-inducing factor (AIF)[23] or by acting at lysosome level[21].

In our previous report[14] we hypothesized that the failure of ZOL to induce apoptosis in cholangiocarcinoma cell lines could be linked to mechanisms such as an altered expression of prosurvival or pro-apoptotic proteins, and/or a constitutive expression of heat shock proteins. In this work we sought to determine whether direct targeting of BCL-2 by using the selective inhibitor ABT-737 could cooperate with ZOL to complete the apoptosis process in TFK-1 and EGI-1 cholangiocarcinoma cell lines. 


\section{MATERIALS AND METHODS}

\subsection{Reagents}

Zoledronic acid (ZOL, ZOMETA ${ }^{\circledR}$, Novartis Europharm, UK) was kindly provided by one of authors (MCB), dissolved in phosphate buffer saline (PBS) and stored as a $5 \mathrm{mM}$ stock solution at $20^{\circ} \mathrm{C}$. The BH3-mimetic ABT-737 was purchased from SelleckChem (Selleck Chemicals, Shanghai, China). Culture medium (RPMI 1640) were purchased from Sigma-Aldrich (St. Louis, MO, USA) while fetal bovine serum (FBS) from Gibco-BRL (Grand Island, NY, USA). Antibodies against BCL-XL (H-5), BCL-2 (C-2), MCL-1 (RC13), and AIF (B-9) were obtained from Santa Cruz Biotechnology (Santa Cruz, Temecula, CA, USA). Primary monoclonal antibodies against HSP27 (G3.1), and inducible HSP72 (C92F3A-5) have been purchased from StressGene (Victoria, BC Canada). Monoclonal antibodies against caspase-3 and PARP-1 were from Cell Signaling Technologies (Beverly, MA, USA); monoclonal anti-actin (AC-40) antibody was from Sigma Aldrich. HRP-conjugated secondary antibodies (Pierce, Rockford, IL, USA) and the enhanced chemiluminescence system (ECL) were from Millipore (Millipore Co, Billerica, MA, USA). Reagents for electrophoresis and blotting analysis were obtained from BIO-RAD Laboratories (Richmond, CA, USA). Mitochondrial depolarization assay was performed by using DePsipher kit (Trevigen, Gaithersburg, MD, USA).

\subsection{Cell culture}

The cholangiocarcinoma cell lines EGI-1 and TFK-1 were obtained from the DSMZ (Deutsche Sammlung von Mikroorganismen und Zellkulturen, Braunschweig, GERMANY) and maintained in RPMI-1640 medium. All media contained antibiotics $(100 \mathrm{U} / \mathrm{ml}$ penicillin, $100 \mu \mathrm{g} / \mathrm{ml}$ streptomycin), and were supplemented with $10 \%$ FCS and with $2 \mathrm{mmol} / \mathrm{L}$ glutamine. All cultures were kept in an incubator at $37^{\circ} \mathrm{C}$ in a water-saturated $5 \% \mathrm{CO} 2$ atmosphere in air. Routine 
subcultivations were carried out every week. Cell morphology was assessed on May-Grünwald stained cells.

\subsection{Crystal violet assay}

Cell number was evaluated by crystal violet staining as described[24]. Briefly, cells were fixed with $1 \%$ formaldehyde and stained with $0.1 \%$ crystal violet in PBS. The unbound dye was removed by washing with water. Bound crystal violet was solubilized with $0.2 \%$ TritonX-100 in PBS. Light extinction which increases linearly with the cell number was analyzed at $570 \mathrm{~nm}$.

\subsection{Clonogenic assay}

Colony formation was determined by seeding cells into a six-well culture plates at a density of 50 cells/cm 2 well and left to adhere overnight. The cells were then incubated in the absence or in the presence of ABT-737 and ZOL, alone or in combination. After 10 day-incubation, the wells were washed twice with PBS, and fixed with $1 \%$ formaldehyde. They were then stained with $0.1 \%$ crystal violet. The colony is defined to consist of at least 40-50 cells. For evaluation of cell growth, colonies were examined under a light microscope. The experiments were repeated thrice and comparable results were obtained.

\subsection{Western blotting}

Total proteins were extracted by lysing the cells with a buffer containing 50mM Tris-HCL, pH 7.4, $150 \mathrm{mM} \mathrm{NaCl}, 5 \mathrm{mM} \mathrm{MgCl} 2,0.5 \mathrm{mM}$ EDTA, $0.1 \%$ SDS and protease inhibitor cocktail followed by ultracentrifugation at $13,000 \mathrm{rpm}$ for $10 \mathrm{~min}$. Protein concentration was determined using a protein assay from BIO-RAD according to the manufacturer's protocol, using BSA as standard. Proteins

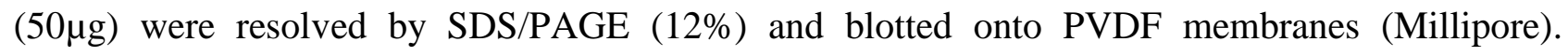
Cytosolic and mitochondrial fractions were generated from cholangiocarcinoma cells using a digitonin-based subcellular fractionation technique[25] and equal volumes of cytosolic and mitochondrial fractions (corresponding to $100 \mu \mathrm{g}$ protein of the cytosolic fraction) were resolved by SDS-PAGE and transferred to PVDF membranes. Immunodetection was carried out in 50mM Tris- 
$\mathrm{HCl}, \mathrm{pH} 7.4,150 \mathrm{mM} \mathrm{NaCl}, 0.1 \%$ Tween $20,5 \%$ non-fat dry milk, with the following primary antibodies: BCL-XL, BCL-2, MCL-1, AIF and caspase-3 were use at a dilution of 1:1000, PARP1 and HSP27 diluted at 1:2000, HSP72 and actin at 1:5000. Then, HRP conjugated secondary antibody at 1:20000 dilutions. Detection was performed using an ECL kit.

\subsection{Mitochondrial Depolarization}

The assay was performed by using the DePsipher kit (Trevigen, Gaithersburg, MD). Briefly, after 72h of drug treatment, the cells were collected, washed with Reaction Buffer, and then suspended in DePsipher (JC-1,5,59,6,69-tetrachloro-1,19,3,39-tetraethyl-benzimidaxolylcarbocyanine iodide) solution (final concentration, $5 \mathrm{mg} / \mathrm{ml}$ ). After incubation at $37^{\circ} \mathrm{C}$ for $20 \mathrm{~min}$, the samples were washed with Reaction Buffer twice and analyzed through the FL1 and FL2 channels using a Coulter EPICS XL_MCL cytometer (Coulter Co., Miami, FL, USA).

\subsection{Statistical analysis}

Statistical significance of differences in single-agent versus combined treated cells was determined using the paired T-test. The minimal level of significance was $\mathrm{P}<0.05$. The half-maximal inhibition constant (IC50) was determined using the nonlinear regression program CalcuSyn (Biosoft, Cambridge, UK). Combination index (CI) was calculated using isobologram analysis of Chou and Talalay[26] based on the equation: $C I=(D 1 / D x 1)+(D 2 / D x 2)+(D 1 \cdot D 2) /(D x 1 \cdot D x 2)$, where D1 and D2 are the doses of drug1 and drug2 that have $\mathrm{x}$ effect when used in combination, and Dx1 and Dx2 are the doses of drug1 and drug2 that have $\mathrm{x}$ effect when used alone. CI values $<1$ indicated synergism. In particular, CIs <0.3, 0.3-0.7 and 0.7-0.85 are considered to indicate strong synergism, synergism and moderate synergism, respectively. CI values $>0.85$ and $<1$ are considered to indicate additivity whereas values $>1$ indicated antagonism. 


\section{RESULTS}

\section{BCL-2 protein family and $\mathrm{HSPS}$}

In our previous paper[14] the large constitutive expression of BCL-XL proteins in both TFK-1 and EGI-1 cells has prompt us to speculate a potential involvement of pro-survival BCL-2 family members in ZOL-induced apoptosis resistance. As shown in Figure 1A, BCL-2 protein is significantly expressed in both cell lines with higher level in EGI-1 cells. The higher level of BCL-2 expression in this cell line is due to a characteristic abnormal chromosome 18, add(18)(q23)[27] linked to the presence of two amplicons as indicated in EGI-1 datasheet. Furthermore, a large expression of MCL-1 in TFK-1 cells, as already shown by Taniai et al.[18], was observed, while EGI-1 cells showed a low level of this protein. This different expression of MCL-1 in our cell lines somehow reduces the role of this protein in influencing apoptosis resistance following ZOL treatment and rather emphasizes the role of BCL-2/BCL-XL in ZOL-induced apoptosis resistance. Interestingly, both cell lines show constitutively high level of expression HSP72, not further modified after heat shock induction at $44^{\circ} \mathrm{C}$ for 30 minutes (figure 1B), but only TFK-1 showed a constitutive expression of HSP27. The absence of HSP27 in EGI-1 cells is not due to inability of cells to express this protein since it was markedly induced after heat shock. 


\section{Effect of ABT-737 on cell proliferation}

Before to test whether the selective inhibition of BCL-2 could sensitize cholangiocarcinoma cells to ZOL treatment, we first investigated the effect of a $\mathrm{BH} 3$-mimetic as single agent on TFK-1 and EGI-1 cells. The choice to use ABT-737 arose from three considerations: (1) the marked divergent pattern of MCL-1 and BCL-2 expression in our cholangiocarcinoma cell lines (see Figure 1A), (2) the high affinity of ABT-737 (Ki $\leq 1 \mathrm{nmol} / \mathrm{L}$ [28] for BCL-2, BCL-XL, BCL-W) in comparison with obatoclax (Ki $220 \mathrm{nmol} / \mathrm{L}$ for BCL-2 and $500 \mathrm{nmol} / \mathrm{L}$ for BCL-XL, BCL-W, and MCL1[19]), and (3) agents with high affinity provide good chances to overcome cancer cell drug resistance, whereas low-affinity agents may introduce unexpected responses. Due to the abovementioned considerations, TFK-1 and EGI-1 cells were treated with ABT-737 (1-50 $\mu \mathrm{M})$ for 72 h, followed by crystal violet staining. As revealed by Figure 2 (upper panel), the treatment with ABT-737 significantly inhibited proliferation/survival of both cholangiocarcinoma cells with comparable potencies. The estimated IC50 value was in the low $\mu$ molar concentration range in EGI1 cells (4.62 $\mu$ M C.I 95\%: 3.4-6.2), whereas a moderately higher (4-fold) ABT-737 concentration (17.15 $\mu$ M C.I 95\%: 6.46-40.5) was required to achieve 50\% cell inhibition in TFK-1 cells.

\section{Apoptosis assessment}

Since a recent mechanistic study suggests a key role of ABT-737 in the ROS generation which in turn induce apoptotic machinery[29] we evaluated the occurrence of PARP-1 activation (cleavage) or/and apoptosis stigmata (such as activation of caspases) by biochemical criteria. ABT-737 determined a dose-dependent PARP-1 activation (see Figure 2, lower panel). Activation of PARP-1 protein was already evident at $1 \mu \mathrm{M}$ and $10 \mu \mathrm{M}$ in EGI-1 and TFK-1 cells, respectively, without concomitant cleavage of caspase-3/9. On the contrary, the cleavage of caspase- 9 and caspase-3 was observed only at the highest concentrations tested (10-25 $\mu \mathrm{M}$ and 25-50 $\mu \mathrm{M}$ for EGI1 and TFK-1 cells, respectively). Interestingly, in TFK-1 a marked reduction of MCL-1 at the highest ABT-737 
concentration used was observed (concomitant with the caspases cleavage), while a moderate change in BCL-2 level, compared to untreated cells, was present in EGI-1 cells.

\section{ABT-737 cooperates with ZOL to inhibit cell proliferation}

When tested as single agent, ABT-737 potently inhibited the survival of cholangiocarcinoma cells only at high concentrations (see Figure 2, upper panel). It was then investigated whether the antagonism of the BCL-2 function by ABT-737 could confer apoptosis sensitivity in ZOL-treated cells. Combination experiments using drugs concentration close to IC50 (15 $\mu \mathrm{M}$ ZOL[14] and 3 $\mu \mathrm{M}$ ABT-737 in EGI-1 cells; $30 \mu \mathrm{M}$ ZOL[14] and $10 \mu \mathrm{M}$ ABT-737 in TFK-1 cells) were performed. The molecules above mentioned when used as single agent at the same concentration determined moderate modification of proliferation pattern (see Figure 2) and no variation of the expression or activation of pro-apoptotic proteins nor cell morphology (see Figure 5).

The cholangiocarcinoma cells treated simultaneously with ABT-737 and ZOL showed an increased sensitivity mostly prominent in EGI-1 cells in which an almost fully inhibition of proliferation occurred (97\%, see Figure 3A), meanwhile in TFK-1 cells the inhibition was not more than $81 \%$. As shown in Figure 3A, the concomitant exposure of cells to both drugs determined a synergic effect in both cell lines: TFK-1 cells: ABT-737 $10 \mu \mathrm{M}+$ ZOL 10-50 $\mu \mathrm{M}$, CI: 0.5-0.77, Paired T-test P-value=0.0181; EGI-1 cells: ABT-737 $3 \mu \mathrm{M}+$ ZOL 10-50 $\mu \mathrm{M}$ CI: 0.106-0.128, Paired T-test Pvalue $=0.0488$.

Because of the pronounced cytotoxic effects of ABT-737 and ZOL combination, we then verified if ZOL associated with ABT-737 could, similarly, affect the ability of EGI-1 and TFK-1 cells to form colonies in vitro (as a surrogate of invasive ability of cancer cells). After 10 days in culture both EGI-1 and TFK-1 cells, seeded at 50 cells $/ \mathrm{cm}^{2}$, formed a large number of colonies clearly visible at naked eye (see Figure 3B, upper left wells). However, when cells were grown for 10 days in the presence of 4 or $8 \mu \mathrm{M}$ of ZOL, the number and size of TFK-1 and EGI-1 colonies were markedly reduced. On the contrary, cells treated with $3 \mu \mathrm{M}$ of ABT-737 formed colonies clearly visible at 
naked eye. When treated with 4 or $8 \mu \mathrm{M}$ ZOL and $3 \mu \mathrm{M}$ of ABT-737, both cell lines form little, if any, visible colonies. The combined treatment determined also alterations of cell morphology (Figure 5, upper panel). Control cultures showed the typical morphology of cholangiocarcinoma cells (cuboidal to low-columnar) with rounded or slightly polygonal nuclei (see left pictures, upper panel). In the presence of 15 or $30 \mu \mathrm{M}$ ZOL treatment both cell lines showed an increase in size, more evident in EGI-1 cells, that represents the S-phase block induced by ZOL, as already indicated in our previous work. The combination of the two drugs determined marked changes in cell morphology indicated by narrowed cells coupled with a sharp reduction of cells number, mainly observed in EGI-1 cells. Similar changes in morphology and numbers, even if less marked, were also observed in TFK-1 cells.

\section{Mitochondrial depolarization assessment}

It is known that BCL-2 inhibitors induce mitochondrial damage by several ways: in particular, ABT737 was reported to elicit significant ruptures of the outer mitochondrial membrane with concomitant collapse of mitochondrial membrane potential[30]. In apoptotic cells with collapsed mitochondrial membranes cationic dye cannot accumulate within mitochondria, remaining in the cytoplasm as green fluorescent monomeric form. On the contrary, in cells with healthy mitochondria the dye fluoresces brightly red in its multimeric form. Taking advantage of a procedure involving the preferential conformation of cationic dye in mitochondria (alive cells) or in cytoplasm (apoptotic cells), we then examined the mechanism that underlies the marked reduction of cells number and the modifications of cell morphology caused by ABT-737. TFK-1 cells were treated with $30 \mu \mathrm{M}$ ZOL and $10 \mu \mathrm{M}$ ABT-737 alone or in combination (Fig.4A), while EGI-1 cells were treated with $15 \mu \mathrm{M}$ ZOL and $3 \mu \mathrm{M}$ ABT-737 alone or in combination (Fig.4B). The ZOL treatment ( 30 or $15 \mu \mathrm{M}$ ) induced a 2.3 to 3.2 fold increase, compared to untreated cells, of harmedmitochondria cells in TFK-1 and EGI-1 cells, respectively $\left(\chi^{2}\right.$ P-values $\left.<0.001\right)$. The treatment of EGI-1 cells with $3 \mu \mathrm{M}$ ABT-737 determined a 5.2 fold increase of damaged cells, coupled with a 
scarce inhibition of proliferation observed at the same concentration (around 20\%, see Figure 2 upper panel). Similarly, in TFK-1 cells $10 \mu \mathrm{M}$ ABT-737 induced little, if any, effect on mitochondrial membrane (only 1.3-fold of damaged cells) as well as in inhibiting cell proliferation (around $20 \%$ of inhibition, Figure 2). When both cell lines were treated with a combination of the two drugs, the results clearly indicate a 9-and 5-fold increase of EGI-1 and TFK-1 cells, respectively, with damaged mitochondrial membranes.

\section{ABT 737 cooperates with ZOL in completing the execution phase of apoptosis}

No processing of procaspase-3 to active caspase-3 was detected in EGI-1 cells treated with single drug (3 $\mu \mathrm{M}$ ABT-737 or $15 \mu \mathrm{M}$ ZOL). Similarly, no caspase-3 activation was observed in TFK-1 cells treated with single drug (10 $\mu \mathrm{M}$ ABT-737 or with $30 \mu \mathrm{M}$ ZOL alone) (Fig. 5, lower panel). However, PARP-1 cleavage was detected after treatment with ABT-737 at 3 and $10 \mu \mathrm{M}$ in EGI-1 and TFK-1 cells, respectively. By contrast, the combination of $3 \mu \mathrm{M}$ ABT-737 plus $15 \mu \mathrm{M}$ ZOL (EGI-1 cells) or $10 \mu \mathrm{M}$ ABT-737 plus $30 \mu \mathrm{M}$ ZOL (TFK-1 cells) resulted in marked appearance of active caspase-3 in association with cleavage of PARP-1 protein. The degree of caspase-3 activation and PARP-1 cleavage in response to the combination treatments greatly exceeded the sum of these events occurring in cells treated with single agents. Taken together, these results suggest that ABT737 enhances ZOL-induced apoptosis via mitochondrial membrane depolarization, likely leading to caspases activation and PARP-1 cleavage. Recently, a specific PARP-1 mediated caspaseindependent pathway of cell death leading to the translocation of the mitochondrial apoptosisinducing factor (AIF) via cytoplasm to the nucleus has been described[31]. To analyze the discrepancy between earlier PARP-1 activation in comparison to caspase cleavage in our cell lines, we then verified AIF releasing in the cytoplasm following ABT737 and/or ZOL exposure. Interestingly, we observed AIF release (i.e. its presence in the cytoplasmic phase) only in the combination treatment. 


\section{DISCUSSION}

For an efficient induction of apoptotic machinery, a complete antagonism of all BCL-2 prosurvival proteins is required[32]. Therefore, ineffective tumor cells killing may be due to a partial neutralization of BCL-2 family members often caused by overexpression of several BCL-2 proteins. Although some authors have indicated that the inhibition of BCL-2 proteins family could not be sufficient to overcome the resistance to apoptosis in cholangiocarcinoma cells, however, the increased expression of the members of BCL-2 family has been associated, in several cancer models, to an altered threshold to apoptosis[15, 17, 33]. According to Harnois[17] our results clearly indicate that the alteration of BCL-2 protein members is an intriguing mechanism to explain the chemoresistance of cholangiocarcinoma to several drugs. The overexpression of BCL-2 observed in EGI-1 cells is in striking contrast with the results showed by Okaro[16], where the EGI1 and TFK-1 cells were negative for BCL-2. The overexpression of BCL-2 and BCL-XL family members of the BCL-2 subfamily have been associated in our previous study[14] with the resistance of the TFK-1 and EGI-1 cholangiocarcinoma cells to the ZOL induced apoptosis, and making mandatory the setting up of combination therapies with molecules that target BCL-2. As observed by cytofluorimetric analysis ZOL determined moderate triggering of apoptotic machinery as revealed by a shift of fluorescence, index of loss of mitochondrial potential. However, ZOL was unable to complete the execution phase of apoptosis in both cholangiocarcinoma cell lines. Taken together, our results suggest that ZOL (i) primed cholangiocarcinoma for cell death by blocking prenylation of small GTP proteins[13] which, in turn, induce S-phase arrest[34], ii) triggered the apoptotic machinery via mitochondrial membrane depolarization without, however, completing the execution phase of apoptosis; (iii) ZOL inability to complete the apoptotic pathway was probably multifactorial being potentially linked to high levels of prosurvival proteins belonging to BCL-2 family, to low levels of pro-apoptotic proteins such as BAX or other mechanisms involving the HSPs. The high level of BCL-2 or BCL-XL are likely to sequester apoptotic mediators such BIM, 
BAX and BAD until the apoptotic signals becomes overwhelming and cell death occurs[35]. The characterization of apoptotic proteins pattern in the two cholangiocarcinoma cell lines used in this study has shown interesting differences. In particular, besides the high level of antiapoptotic MCL-1 expressed by TFK-1 cells (potentially linked to an increased apoptosis resistance), EGI-1 cells showed higher levels of BCL-2 (thus suggesting a higher sensitivity toward ABT-737[36]). This constitutive divergent pattern of BCL-2 and MCL-1 expression found in these two cholangiocarcinoma cell lines of similar histological origin, allowed us to investigate the potential role of high or low BCL-2 and/or high or low MCL-1 level in response to the selective BCL-2 inhibitor ABT-737. ABT-737 by interacting with BCL-2 protein and consequently blocking BCL-2 action (i.e. the sequestering main pro-apoptotic activators and effectors) might contribute to reduce the apoptosis triggering threshold. Our data indicated that ABT-737 causes apoptosis occurrence, assessed by caspase 3/9 activation and PARP-1 cleavage, in both cell lines only at concentration above IC50. These results are in agreement with the hypothesis that ABT-737 at low concentrations exerts only a minimal cytotoxic/cytostatic effect behaving as an adjuvant agent for apoptosis induction. When ABT-737 was used in combination with ZOL it works synergistically to complete the execution phase of apoptosis in both cholangiocarcinoma cell lines. This synergism was clearly evident also at molecular level, as assessed by dramatic increase of mitochondrial membrane depolarization, caspase-3 activation and PARP-1 cleavage. Although ABT-737 was able to cause in EGI-1 cells a marked increase of sensitivity to apoptosis mediated by ZOL, this increment, in TFK1 cells, was less pronounced. In short, ZOL treatment could behave as "priming" agent[37] which induces S-phase arrest, an insufficient pro-apoptotic signal, while ABT-737 by blocking BCL-2 and BCL-XL action lowers the threshold at which apoptosis may occur. The ZOL or ABT-737-induced apoptosis resistance, observed in cholangiocarcinoma cells when used as single agent prompted us to speculate the plausible involvement of HSP72-dependent PARP-1 inactivation and/or an HSP27mediated BAX inactivation that may contribute to explain the increased cell survival. It is worth to note that although PARP-1 was already activated at low concentrations of ABT-737, we did not 
observed any caspase activation. This outcome could be associated to the loss of GSH following ABT-737 treatment as recently reported[29]. The GSH depletion increases ROS generation, which determines PARP-1 activation, and in turn induction of AIF translocation in the extra-mitochondrial compartment with consequent chromatin condensation[29, 35]. Our results unexpectedly show that the early PARP-1 activation is not associated to AIF translocation from the mitochondria to the cytoplasm. This discrepancy could be explained to the inhibitory action of the constitutively expressed HSP72 towards AIF. HSP72 is the only protein known to physically interact with AIF. Moreover, in a cell-free system HSP72 prevented the AIF-induced chromatin condensation of purified nuclei. Thus, cells overexpressing HSP72 were protected against the apoptogenic effects of AIF targeted to the extramitochondrial compartment, either by microinjection of the recombinant AIF protein or by transfection with AIF. Moreover, it has been reported that the ATPase domain of HSP72 plays a key role in sequestering AIF in the cytosol, thereby inhibiting AIF nuclear translocation[38]. A potential additional mechanism that may contribute to increase the apoptosis resistance in TFK-1 cells is represented by the constitutive expression of pro-survival HSP27[21, 39, 40]. This protein antagonizes BAX-mediated mitochondrial injury by inhibiting conformational activation of BAX thus reducing cytochrome $\mathrm{c}$ and AIF leakage and increasing significantly cell survival[37, 41]. The resistance of EGI-1 and TFK-1 cholangiocarcinoma cell lines exposed to ABT-737 is multifactorial and could be ascribed to the presence of high levels of MCL-1 prosurvival protein (TFK-1), low level of BCL-2 (TFK-1), overexpression of HSP72 (TFK-1, EGI-1) or HSP27 (TFK-1). However, the results so far obtained from combined treatment seem to suggest that the apoptosis resistance pathway could be not completely related to BCL-2, BCL-XL or MCL1 inactivation, and that the inhibition of BCL-2 protein family is necessary but not sufficient to achieve a complete overcoming of resistance. Recent papers have shown that, although the MCL-1 levels may well influence the ABT-737 sensitivity, on the other hand, its lack unlikely causes sensitivity to BCL-2 antagonism nor the most critical in lymphoma and in solid tumors[33, 42]. Finally, our results showed that ZOL treatment in the absence of the prosurvival protein MCL-1 
was not sufficient neither necessary to sensitize cholangiocarcinoma cells to ZOL-induced apoptosis, thus reserving to BCL-2/BCL-XL and HSPs, the role of true protagonists in apoptosis resistance. The clinical relevance of our results remains to be established. However, the data provided in this study suggest that determining the expression levels of pro-survival proteins should help to discriminate those patients affected by cholangiocarcinoma with a potential responsiveness to chemotherapy. Moreover, preoperative information could provide a basis for enrolling those patients liable to undergo a combined therapy with a BH-3 mimetic. The use of this molecule could restore tumor cell sensitivity towards a broad range of apoptosis-inducing therapies designed to delay tumor progression. Furthermore, given the limited toxicity of ZOL in preclinical and clinical studies[43-45] we expected that the integrated therapy, i.e. ZOL combined with ABT-737, will be better tolerated and able to be delivered with greater efficacy and less toxicity than chemotherapy regimens currently used for cholangiocarcinoma. This combined therapy should merit a preclinical investigation for a potential use particularly, for refractory chemotherapy-regimen and recurrent cholangiocarcinoma. 


\section{Acknowledgements}

A.A. Romani is funded by a fellowship from Regione Emilia-Romagna, Progetto Re.Ga.Str. Azienda

Ospedaliero-Universitaria di Parma, Parma, Italy. S. Desenzani is funded by a grant from Cariparma Foundation, Parma, Italy. 
DISCLOSURES: NONE 


\section{LEGEND TO FIGURES}

Figure 1. (A) Detection by Western blotting of basal level of BCL-XL, BCL-2, MCL-1 in TFK-1 and EGI-1 cells. (B) TKF-1 and EGI-1 cells were heat-shocked (HS) or not at $44^{\circ} \mathrm{C}$ for $30 \mathrm{~min}$. Cells were left to $37^{\circ} \mathrm{C}$ overnight and then cell lysates were analyzed by Western blotting using a monoclonal antibodies against HSP72, HSP27 or actin. Results are from a representative experiment. The experiment, repeat three times, yielded similar results.

Figure 2. Upper Panel: ABT-737 inhibits TFK-1 and EGI-1 cell growth. Cells were exposed to ABT737 at a concentration ranging from 1 to $50 \mu \mathrm{M}$. Following $72 \mathrm{~h}$ of incubation growth inhibition was analyzed by crystal violet assay. Dose-effect plot of ABT-737 treatment is presented. The experiment was performed three times yielding similar results. A representative experiment is shown. Lower panel: Detection of PARP-1, cleaved Caspase-9 and -3, BCL-2 and MCL-1 in TFK-1 and EGI-1 cells after 72h of ABT-737 treatment $(1,3,10,25,50 \mu \mathrm{M})$. Cell lysates were analysed on Western blotting. Results are from a representative experiment. Each experiment, repeat three times, yielded similar results.

Figure 3. (A) Effect of ZOL alone and Combined treatment (ZOL + ABT-737) on inhibition of TFK-1 and EGI-1 cell proliferation. Cells were exposed to ZOL $(1-50 \mu \mathrm{M})$ in the absence or in the presence of ABT-737 (3 or $10 \mu \mathrm{M}$ in EGI-1 and in TFK-1, respectively). Following 72h of incubation the growth inhibition was evaluated with crystal violet assay. Data are presented as mean \pm S.D. of three independent experiments. The synergism was then verified by calculating the combination index (CI) (see text for details). (B) Colony formation assay. Influence of combination treatment of $3 \mu \mathrm{M}$ of ABT737 with $4 \mu \mathrm{M}$ or $8 \mu \mathrm{M}$ of ZOL on the ability of TFK-1 and EGI-1 to form colonies.

Figure 4. Effect of ABT-737 and ZOL on mitochondrial membrane potential. (A) TFK-1 and (B) EGI-1 cells were seeded at $1,5 \times 10^{5}$. After $72 \mathrm{~h}$ exposure to ABT-737 ( $3 \mu \mathrm{M}$ for EGI-1 and $10 \mu \mathrm{M}$ TFK-1)

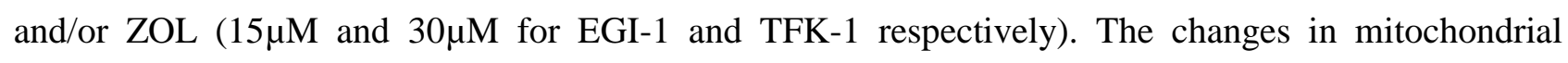
membrane potentials were assessed by cytometric analysis of cells stained with DePsipher kit as described in Methods section. A shift from red to green fluorescence denotes dissipation of 
mitochondrial membrane potential. The percentage of cells with mitochondrial membrane depolarization is indicated. The experiment was performed three times yielding similar results.

Figure 5. Upper panel: Cholangiocarcinoma cell changes induced after ABT-737 and ZOL combination treatment on cell morphology. EGI-1 and TFK-1 cells were plated and treated for $72 \mathrm{~h}$ with ABT737 and ZOL alone or in combination. Then morphology was evaluated after May-Grünwald

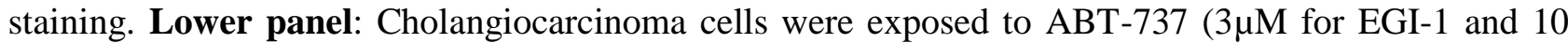
$\mu \mathrm{M}$ TFK-1 cells) and/or ZOL (15 $\mu \mathrm{M}$ and $30 \mu \mathrm{M}$ for EGI-1 and TFK-1 cells, respectively). Following $72 \mathrm{~h}$ of incubation cell proteins were extracted, separated by SDS-PAGE, blotted on PVDF membrane and treated with PARP-1, Caspase-3, AIF or actin antibodies. Results are from a representative experiment. Each experiment, repeat three times, yielded similar results. 


\section{REFERENCES}

[1] Khan SA, Thomas SC, Davidson BR, Taylor-Robinson SD (2005) Cholangiocarcinoma. Lancet 366: 1303-1314

[2] Reddy SB, Patel T (2006) Current approaches to the diagnosis and treatment of cholangiocarcinoma. Curr Gastroenterol Rep 8: 30-7

[3] Aljiffry M, Walsh MJ, Molinari M (2009) Advances in diagnosis, treatment and palliation of cholangiocarcinoma: 1990-2009. World J Gastroenterol 15: 4240-62

[4] Blechacz B, Gores GJ (2008) Cholangiocarcinoma: advances in pathogenesis, diagnosis, and treatment. Hepatology 48: 308-21

[5] Czito BG, Anscher MS, Willett CG (2006) Radiation therapy in the treatment of cholangiocarcinoma. Oncology (Williston Park) 20: 873-84; discussion 886-8, 893-5

[6] Mazhar D, Stebbing J, Bower M (2006) Chemotherapy for advanced cholangiocarcinoma: what is standard treatment? Future Oncol 2: 509-14

[7] Dingle BH, Rumble RB, Brouwers MC (2005) The role of gemcitabine in the treatment of cholangiocarcinoma and gallbladder cancer: a systematic review. Can J Gastroenterol 19: 711-6

[8] Valle JW, Wasan H, Johnson P, Jones E, Dixon L, Swindell R (2009) Gemcitabine alone or in combination with cisplatin in patients with advanced or metastatic cholangiocarcinomas or other biliary tract tumours: a multicentre randomised phase II study - The UK ABC-01 Study. British journal of cancer 101: 621-627

[9] Hanahan D, Weinberg RA (2000) The hallmarks of cancer. Cell 100: 57-70

[10] Green DR, Kroemer G (2004) The pathophysiology of mitochondrial cell death. Science 305: 626-9

[11] Menakongka A, Suthiphongchai T Involvement of PI3K and ERK1/2 pathways in hepatocyte growth factor-induced cholangiocarcinoma cell invasion. World J Gastroenterol 16: 713-22

[12] Schmitz KJ, Lang H, Wohlschlaeger J, Sotiropoulos GC, Reis H, Schmid KW, Baba HA (2007) AKT and ERK1/2 signaling in intrahepatic cholangiocarcinoma. World J Gastroenterol 13: 6470-7

[13] Luckman SP, Hughes DE, Coxon FP, Graham R, Russell G, Rogers MJ (1998) Nitrogencontaining bisphosphonates inhibit the mevalonate pathway and prevent post-translational prenylation of GTP-binding proteins, including Ras. J Bone Miner Res 13: 581-9

[14] Romani AA, Desenzani S, Morganti MM, La Monica S, Borghetti AF, Soliani P (2009)

Zoledronic acid determines S-phase arrest but fails to induce apoptosis in cholangiocarcinoma cells. Biochem Pharmacol 78: 133-41

[15] Danial NN (2007) BCL-2 family proteins: critical checkpoints of apoptotic cell death. Clin Cancer Res 13: 7254-63

[16] Okaro AC, Deery AR, Hutchins RR, Davidson BR (2001) The expression of antiapoptotic proteins Bcl-2, Bcl-X(L), and Mcl-1 in benign, dysplastic, and malignant biliary epithelium. J Clin Pathol 54: 927-32

[17] Harnois DM, Que FG, Celli A, LaRusso NF, Gores GJ (1997) Bcl-2 is overexpressed and alters the threshold for apoptosis in a cholangiocarcinoma cell line. Hepatology 26: 884-90

[18] Taniai M, Grambihler A, Higuchi H, Werneburg N, Bronk SF, Farrugia DJ, Kaufmann SH, Gores GJ (2004) Mcl-1 mediates tumor necrosis factor-related apoptosis-inducing ligand resistance in human cholangiocarcinoma cells. Cancer Res 64: 3517-24

[19] Nguyen M, Marcellus RC, Roulston A, Watson M, Serfass L, Murthy Madiraju SR, Goulet D, Viallet J, Belec L, Billot X, Acoca S, Purisima E, Wiegmans A, Cluse L, Johnstone RW, Beauparlant P, Shore GC (2007) Small molecule obatoclax (GX15-070) antagonizes MCL-1 and overcomes MCL-1-mediated resistance to apoptosis. Proc Natl Acad Sci U S A 104: 19512-7 
[20] van Delft MF, Wei AH, Mason KD, Vandenberg CJ, Chen L, Czabotar PE, Willis SN, Scott CL, Day CL, Cory S, Adams JM, Roberts AW, Huang DC (2006) The BH3 mimetic ABT-737 targets selective Bcl-2 proteins and efficiently induces apoptosis via Bak/Bax if Mcl-1 is neutralized. Cancer Cell 10: 389-99

[21] Lanneau D, Brunet M, Frisan E, Solary E, Fontenay M, Garrido C (2008) Heat shock proteins: essential proteins for apoptosis regulation. J Cell Mol Med 12: 743-61

[22] Beere HM, Green DR (2001) Stress management - heat shock protein-70 and the regulation of apoptosis. Trends Cell Biol 11: 6-10

[23] Ravagnan L, Gurbuxani S, Susin SA, Maisse C, Daugas E, Zamzami N, Mak T, Jaattela M, Penninger JM, Garrido C, Kroemer G (2001) Heat-shock protein 70 antagonizes apoptosis-inducing factor. Nat Cell Biol 3: 839-43

[24] Gillies RJ, Didier N, Denton M (1986) Determination of cell number in monolayer cultures. Anal Biochem 159: 109-13

[25] Fumarola C, La Monica S, Alfieri RR, Borra E, Guidotti GG (2005) Cell size reduction induced by inhibition of the mTOR/S6K-signaling pathway protects Jurkat cells from apoptosis. Cell Death Differ 12: 1344-57

[26] Chou TC, Talalay P (1984) Quantitative analysis of dose-effect relationships: the combined effects of multiple drugs or enzyme inhibitors. Adv Enzyme Regul 22: 27-55

[27] Taniwaki M, Sliverman GA, Nishida K, Horiike S, Misawa S, Shimazaki C, Miura I, Nagai M, Abe M, Fukuhara S, et al. (1995) Translocations and amplification of the BCL2 gene are detected in interphase nuclei of non-Hodgkin's lymphoma by in situ hybridization with yeast artificial chromosome clones. Blood 86: 1481-6

[28] Kang MH, Reynolds CP (2009) Bcl-2 inhibitors: targeting mitochondrial apoptotic pathways in cancer therapy. Clin Cancer Res 15: 1126-32

[29] Howard AN, Bridges KA, Meyn RE, Chandra J (2009) ABT-737, a BH3 mimetic, induces glutathione depletion and oxidative stress. Cancer Chemother Pharmacol 65: 41-54

[30] Vogler M, Weber K, Dinsdale D, Schmitz I, Schulze-Osthoff K, Dyer MJ, Cohen GM (2009) Different forms of cell death induced by putative BCL2 inhibitors. Cell Death Differ 16: 1030-9

[31] Yu SW, Wang H, Poitras MF, Coombs C, Bowers WJ, Federoff HJ, Poirier GG, Dawson TM, Dawson VL (2002) Mediation of poly(ADP-ribose) polymerase-1-dependent cell death by apoptosis-inducing factor. Science 297: 259-63

[32] Willis SN, Fletcher JI, Kaufmann T, van Delft MF, Chen L, Czabotar PE, Ierino H, Lee EF, Fairlie WD, Bouillet P, Strasser A, Kluck RM, Adams JM, Huang DC (2007) Apoptosis initiated when BH3 ligands engage multiple Bcl-2 homologs, not Bax or Bak. Science 315: 856-9

[33] Oltersdorf T, Elmore SW, Shoemaker AR, Armstrong RC, Augeri DJ, Belli BA, Bruncko M, Deckwerth TL, Dinges J, Hajduk PJ, Joseph MK, Kitada S, Korsmeyer SJ, Kunzer AR, Letai A, Li C, Mitten MJ, Nettesheim DG, Ng S, Nimmer PM, O'Connor JM, Oleksijew A, Petros AM, Reed JC, Shen W, Tahir SK, Thompson CB, Tomaselli KJ, Wang B, Wendt MD, Zhang H, Fesik SW, Rosenberg SH (2005) An inhibitor of Bcl-2 family proteins induces regression of solid tumours. Nature 435: 677-81

[34] Ory B, Blanchard F, Battaglia S, Gouin F, Redini F, Heymann D (2007) Zoledronic acid activates the DNA S-phase checkpoint and induces osteosarcoma cell death characterized by apoptosis-inducing factor and endonuclease- $G$ translocation independently of p53 and retinoblastoma status. Mol Pharmacol 71: 333-43

[35] Esposito E, Cuzzocrea S (2009) Superoxide, NO, peroxynitrite and PARP in circulatory shock and inflammation. Front Biosci 14: 263-96

[36] Del Gaizo Moore V, Schlis KD, Sallan SE, Armstrong SA, Letai A (2008) BCL-2 dependence and ABT-737 sensitivity in acute lymphoblastic leukemia. Blood 111: 2300-9 
[37] Havasi A, Li Z, Wang Z, Martin JL, Botla V, Ruchalski K, Schwartz JH, Borkan SC (2008) Hsp27 inhibits Bax activation and apoptosis via a phosphatidylinositol 3-kinase-dependent mechanism. J Biol Chem 283: 12305-13

[38] Ruchalski K, Mao H, Li Z, Wang Z, Gillers S, Wang Y, Mosser DD, Gabai V, Schwartz JH, Borkan SC (2006) Distinct hsp70 domains mediate apoptosis-inducing factor release and nuclear accumulation. J Biol Chem 281: 7873-80

[39] Garrido C, Fromentin A, Bonnotte B, Favre N, Moutet M, Arrigo AP, Mehlen P, Solary E (1998) Heat shock protein 27 enhances the tumorigenicity of immunogenic rat colon carcinoma cell clones. Cancer Res 58: 5495-9

[40] Romani AA, Crafa P, Desenzani S, Graiani G, Lagrasta C, Sianesi M, Soliani P, Borghetti AF (2007) The expression of HSP27 is associated with poor clinical outcome in intrahepatic cholangiocarcinoma. BMC Cancer 7: 232

[41] Bruey JM, Ducasse C, Bonniaud P, Ravagnan L, Susin SA, Diaz-Latoud C, Gurbuxani S, Arrigo AP, Kroemer G, Solary E, Garrido C (2000) Hsp27 negatively regulates cell death by interacting with cytochrome c. Nat Cell Biol 2: 645-52

[42] Certo M, Del Gaizo Moore V, Nishino M, Wei G, Korsmeyer S, Armstrong SA, Letai A (2006) Mitochondria primed by death signals determine cellular addiction to antiapoptotic BCL-2 family members. Cancer Cell 9: 351-65

[43] Bergner R, Diel IJ, Henrich D, Hoffmann M, Uppenkamp M (2006) Differences in nephrotoxicity of intravenous bisphosphonates for the treatment of malignancy-related bone disease. Onkologie 29: 534-40

[44] Tassinari D, Poggi B, Nicoletti S, Fantini M, Tamburini E, Possenti C, Sartori S (2007) Zoledronic acid treatment at home: safety data from an observational prospective trial. J Palliat Med 10: $352-8$

[45] von Moos R (2005) Bisphosphonate treatment recommendations for oncologists. Oncologist 10 Suppl 1: 19-24 